University of Nebraska - Lincoln

DigitalCommons@University of Nebraska - Lincoln

Fluorescence spectra and elastic scattering characteristics of atmospheric aerosol in Las Cruces, New Mexico, USA: Variability of concentrations and possible constituents and sources of particles in various spectral clusters

\author{
R.G. Pinnick \\ US Army Research Laboratory \\ E. Fernandez \\ New Mexico State University \\ J.M. Rosen \\ New Mexico State University \\ S.C. Hill \\ US Army Research Laboratory \\ Y. Wang \\ US Army Research Laboratory \\ See next page for additional authors \\ Follow this and additional works at: https://digitalcommons.unl.edu/usarmyresearch
}

Pinnick, R.G.; Fernandez, E.; Rosen, J.M.; Hill, S.C.; Wang, Y.; and Pan, Y.L., "Fluorescence spectra and elastic scattering characteristics of atmospheric aerosol in Las Cruces, New Mexico, USA: Variability of concentrations and possible constituents and sources of particles in various spectral clusters" (2013). US Army Research. 211.

https://digitalcommons.unl.edu/usarmyresearch/211

This Article is brought to you for free and open access by the U.S. Department of Defense at DigitalCommons@University of Nebraska - Lincoln. It has been accepted for inclusion in US Army Research by an authorized administrator of DigitalCommons@University of Nebraska - Lincoln. 


\section{Authors}

R.G. Pinnick, E. Fernandez, J.M. Rosen, S.C. Hill, Y. Wang, and Y.L. Pan 


\title{
Fluorescence spectra and elastic scattering characteristics of atmospheric aerosol in Las Cruces, New Mexico, USA: Variability of concentrations and possible constituents and sources of particles in various spectral clusters
}

\author{
R.G. Pinnick ${ }^{\mathrm{a}, \mathrm{b}}$, E. Fernandez ${ }^{\mathrm{b}}$, J.M. Rosen ${ }^{\mathrm{b}}$, S.C. Hill ${ }^{\mathrm{a}}$, Y. Wang ${ }^{\mathrm{a}}$, Y.L. Pan ${ }^{\mathrm{a}, *}$ \\ ${ }^{a}$ US Army Research Laboratory, 2800 Powder Mill Road, Adelphi, MD 20783, USA \\ ${ }^{\mathrm{b}}$ Department of Physics, New Mexico State University, Las Cruces, NM 88003, USA
}

\section{H I G H L I G H T S}

- Possible sources of fluorescent atmospheric aerosol particle.

- Time series of atmospheric aerosol concentration in various spectral clusters.

- UV-LIF spectra and nephelometer scattering of atmospheric aerosol particles.

- Integrated fluorescence spectral profiles vary with time.

\section{A R T I C L E I N F O}

\section{Article history:}

Received 10 May 2012

Received in revised form

10 September 2012

Accepted 12 September 2012

\section{Keywords:}

Atmospheric aerosol particles

Fluorescence spectra

Elastic scattering

Clustered spectra

Integrated spectra

Time resolved

\begin{abstract}
A B S T R A C T
The UV-excited laser-induced-fluorescence (UV-LIF) spectra of single atmospheric particles and the three-band integrating-nephelometer elastic scattering of atmospheric aerosol were measured during four approximately 24-h periods on May 2007 in Las Cruces, New Mexico, USA. Aerosol scattering measurements in the nephelometer red channel (50-nm band centered at $700-\mathrm{nm}$ ) ranged from around 3-10 times the molecular (Rayleigh) scattering background. On average $22.8 \%$ of particles with size greater than about $1 \mu \mathrm{m}$ diameter have fluorescence above a preset fluorescence threshold. A hierarchical cluster analysis indicates that most of the single-particle UV-LIF spectra fall into about 10 categories (spectral clusters) as found previously at other geographic sites (Pinnick et al., 2004; Pan et al., 2007). The clusters include spectra characteristic of various humic/fulvic acids, humic-like-substances (HULIS), chemically aged terpenes, fungal spores, polycyclic aromatic hydrocarbons, bacteria, cellulose/ pollens, and mixtures of various organic carbon compounds. By far the most populated cluster category is similar to those of chemically aged terpenes/humic-materials; on average this population comprises about $62 \%$ of fluorescent particles. Clusters with spectra similar to that of some HULIS aerosol contain on average $10.0 \%$ of particles; those characteristic of some fungal spores (or perhaps mixtures of aromatic organic compounds) $8.4 \%$ of particles; bacteria-like spectra $1.6 \%$ of particles; and cellulose/pollen-like spectra $0.8 \%$ of particles. Measurements of fluorescent particles over relatively short ( $24 \mathrm{~min}$ ) periods reveal that the concentrations of particles in the most populated clusters are highly correlated, suggesting that the particles populating them derive from the same region; these particles might be composed of crustal material coated with secondary organic carbon. On the other hand, concentrations of particles having cellulose-like spectra are generally uncorrelated with those in any other cluster. No clear distinction in fluorescent aerosol characteristics can be seen for different air mass trajectories arriving at the sampling site, suggesting that fluorescent aerosol particles are primarily of local origin. Integrations of the single-particle UV-LIF spectra over approximate $24 \mathrm{~h}$ time intervals reveal two broad peaks around $350 \mathrm{~nm}$ and $450 \mathrm{~nm}$ (for $263 \mathrm{~nm}$ excitation); the $450 \mathrm{~nm}$ peak is somewhat similar to that measured previously for water soluble organic carbon derived from aerosol collections. The $350 \mathrm{~nm}$ peak apparently has not been seen before in measurements of aerosol collections and may derive from nonsoluble primary biological aerosol particles such as fungal spores. Further measurements are needed to investigate in more detail the generality of these results.
\end{abstract}

Published by Elsevier Ltd.

\footnotetext{
* Corresponding author.

E-mail addresses: yongle.pan.civ@mail.mil, yongle.pan@arl.army.mil (Y.L. Pan).
} 


\section{Introduction}

As discussed in the supplement to this report, recent journal reports reflect growing appreciation of the impact of atmospheric particulate matter containing organic carbon and biological material on such diverse fields of science as human health and earth climate. It has been shown that fluorescence spectroscopy can be used to broadly classify organic compounds, including biological material, in atmospheric aerosol; non-organic compounds are in general only weakly fluorescent. A number of rudimentary measurements of the fluorescence emission spectra of a variety of samples bearing on the characterization of atmospheric organic aerosol have been reported. These are enumerated in the supplement and include: a) water soluble extracts of atmospheric aerosol filter collections, b) filter collections of atmospheric fog and cloud water, c) collections of rain water, and d) aerosol samples collected by impaction into Petri dishes containing culture media, followed by growth and isolation of colonies, culturing again, followed by spray atomization of the isolated bacteria and measurement of the spray LIF spectra.

However, unlike these studies of atmospheric collections above, here we focus on classification of fluorescence spectra of single particles in the atmospheric aerosol population by exploiting our technology for in situ measurement of single particle fluorescence spectra (Pinnick et al., 2004; Pan et al., 2007). Also, unlike most previous studies, we measure all atmospheric aerosol particles (with diameters ranging from about 1 to $10 \mu \mathrm{m}$ ), regardless of their volatility or whether or not they are water-soluble, as long as their fluorescence exceeds the detection limit used. Thus our measurements include both secondary organic carbon (SOC) particles and primary biological aerosol particles (PBAP) such as plant, animal, and insect debris, fungal spores, pollens, and bacteria that may not be soluble in water. In addition, unlike collections, our singleparticle measurements are not smeared by the presence of particles of differing composition in the sample; of course even single particles can be of mixed composition.

Previous in situ measurements of the fluorescence of single atmospheric particles have been made with less expensive and more portable fluorescent aerosol sensors that lack the capability of measuring dispersed spectra; the reader is referred to the supplement of this report for a brief description of these measurements.

The measurements of atmospheric organic carbon aerosols reported here were made during late spring at a moderately populated urban site in an arid region of the southwestern US in the Chihuahuan desert (Las Cruces, New Mexico). The results reveal that a significant fraction of supermicron-sized aerosol particles (on average 23\% at this site during May 2007) have measurable fluorescence (at the laser intensity used in our present instrument), and their fluorescence spectral characteristics are similar to those found previously at sites with distinctly different regional climate [New Haven, Connecticut, and Adelphi, Maryland (Pinnick et al., 2004; Pan et al., 2007)]. Interestingly, the concentrations of particles having spectra that fall into a few distinct classes (spectral clusters) are highly correlated with each other, independent of air mass trajectory. Integrations of single-particle fluorescence spectra over a period of a day reveal peaks around $350 \mathrm{~nm}$ and $450 \mathrm{~nm}$ (for $263 \mathrm{~nm}$ excitation); the $450 \mathrm{~nm}$ peak is similar to that measured previously for water soluble organic carbon (WSOC) derived from aerosol collections. The $350 \mathrm{~nm}$ peak can appear during periods of less than one hour and may derive from non-soluble PBAP such as fungal spores. The results show that in situ measurements of single-particle LIF spectra provide a powerful diagnostic tool for classifying atmospheric organic carbon particles.

\section{Experimental details}

Two complementary aerosol sensors were used to measure aerosol scattering and fluorescence characteristics. A commercial three-wavelength integrating nephelometer (Thermal Systems, $3550 / 3560$ - Rosen et al., 1997) was employed to measure integrated elastic aerosol scattering. The nephelometer collects volumetric scattered light over a range of scattering angles from 7 to $170^{\circ}$ from the direction of forward scattering in three bands centered at 450-, 550-, and 700-nm with band-passes of 50-nm. Nephelometer measurements were made each second and the signals were averaged over 4 min periods. The second aerosol sensor, referred to as the Single Particle Fluorescence Spectrometer (SPFS), measures the (UV-LIF) spectra and elastic scattering from single aerosol particles. The SPFS technology was developed and is continually being refined in our laboratory. The aerosol sampling system, optical system, electronic system, and data acquisition system for the SPFS has been described previously (Pan et al., 2007).

Aerosol was sampled through a $4-\mathrm{cm}$ diameter, 3-m long, conductive hose inserted through the outside wall of a first floor laboratory in Gardiner Hall on the New Mexico State University campus located in Las Cruces. A manifold attached to the hose provided aerosol for both the nephelometer (inlet flow of about $1 \mathrm{~L}$ per second) and a virtual impactor concentrator (Dycor, XMX with inlet flow of about $10 \mathrm{~L}$ per second). The minority outlet flow of the concentrator (nominally about $1 \mathrm{~L}$ per minute) was fed to the SPFS. The concentrator was needed to adequately sample supermicron particles at reasonable rates with the SPFS. The concentrator/SPFS system has a size-dependent sample rate which varies from about $1 \mathrm{~L}$ per minute for $1 \mu \mathrm{m}$ sized particles to a maximum of approximately $100 \mathrm{~L}$ per minute for nominal $5-\mu \mathrm{m}$ particles, and falls off sharply for larger particles (Pinnick et al., 2004). Considering this size-dependent sample rate and typical particle size distributions of aerosol in southern New Mexico during late spring (Pinnick et al., 1993), we estimate that the concentrator/SPFS system samples particles with aerodynamic diameter between $1 \mu \mathrm{m}$ and $5 \mu \mathrm{m}$ at very roughly the same frequency. During measurement campaigns the SPFS was routinely calibrated every few hours with nominal 5 - $\mu \mathrm{m}$ tryptophan particles. We note that the nozzle of the SPFS system occasionally became plugged with debris during the nearly continuous measurements, as evidenced by a precipitous drop in count rate over a period of minutes. These data were eliminated from each data set.

\section{Measurement site}

Measurements were conducted on the campus of New Mexico State University, Las Cruces, New Mexico ( $32.2^{\circ} \mathrm{N}$ latitude; elevation $1200 \mathrm{~m}$ ) located in the Chihuahuan Desert of the southwestern US and northern Mexico. Las Cruces is a moderately populous urban area (metropolitan-area population about 200,000 ) with relatively low precipitation (about $25 \mathrm{~cm}$ per year). The metroplex of El Paso, Texas - Ciudad Juarez, Mexico is located $80 \mathrm{~km}$ to the south. In May dusty conditions are common and mean total aerosol loadings are approximately $25 \mu \mathrm{g}$ per cubic meter (Junker et al., 2004). A somewhat heavily traveled (4-lane) auto thoroughfare (University Avenue) is located $105 \mathrm{~m}$ north from the sample site, which is the same as the NM site reported by Pan et al. (2007).

\section{Fluorescence spectra of atmospheric particles and hierarchical cluster analysis}

A sample of SPFS spectra from 1000 fluorescent particles, normalized and grouped into 10 categories, along with the 
corresponding cluster templates, is presented in Fig. 1. The cluster templates were obtained using 10,000 fluorescence spectra measured at the same site previously in January 2007. The hierarchical cluster analysis technique used has been described previously (Pinnick et al., 2004) and a brief description is available in the supplement to this report.
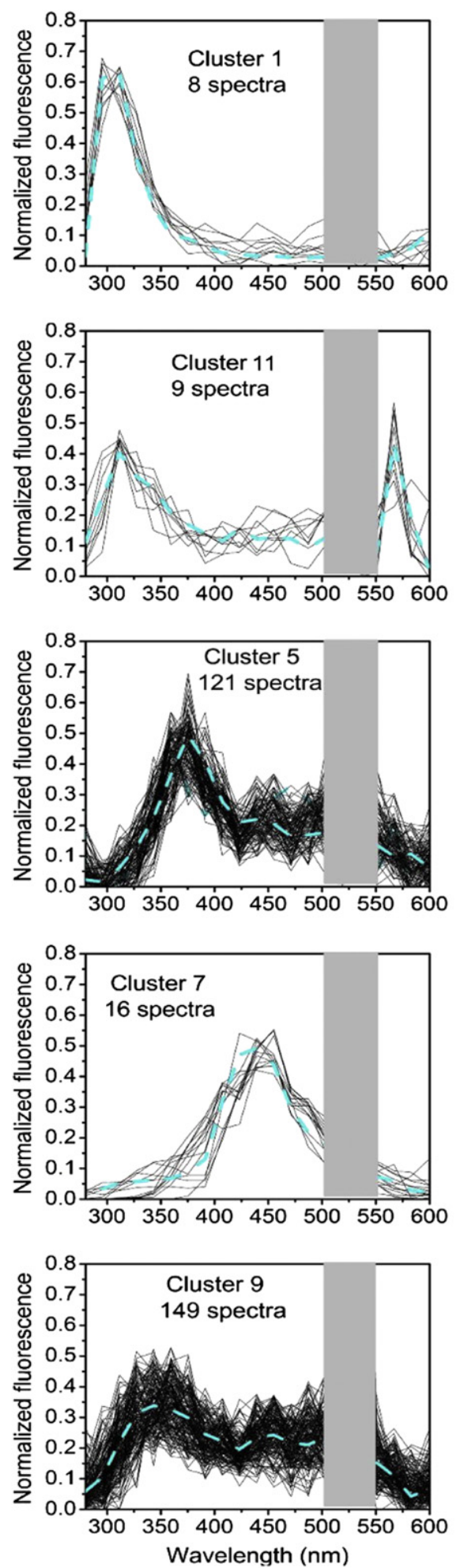

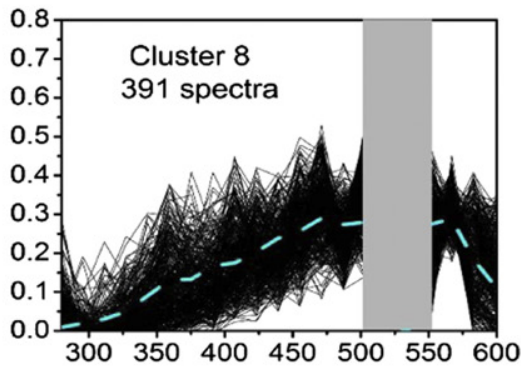

\section{Comparison of spectral clusters with previous measurements; possible organic compounds in particles populating the clusters}

As alluded to in the introduction, there is a fundamental difficulty in comparing the fluorescence spectra from single
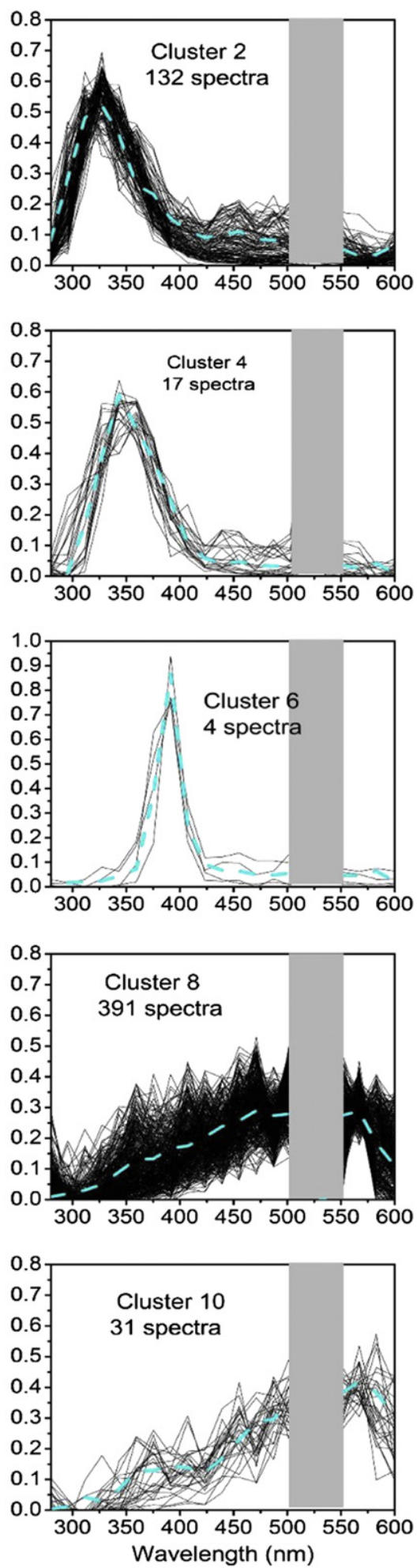

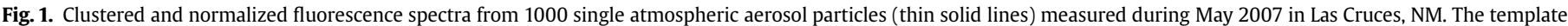

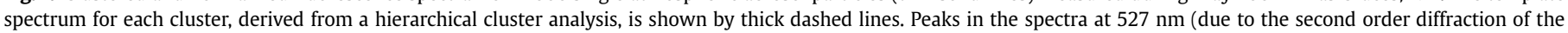
$263 \mathrm{~nm}$ laser line by the grating) are blotted out for sake of clarity. 
atmospheric aerosol particles measured by SPFS with those reported in the literature from bulk collections of atmospheric aerosol, fog, cloud, or rainwater samples. The difficulty is this: each particle typically contains only a few picograms of mass, and the fluorescence spectral classes presented here are for accumulations of similar single-particle spectra, whereas those reported in the literature, with no exceptions we know of, are for aerosol collections that represent an average spectrum for a large number of particles (perhaps $10^{8}-10^{12}$, depending on the amount of sample collected). Also, data for water-soluble fractions of aerosol collections would not include fungal spores, bacteria, pollen fragments, etc.

The average fluorescence spectrum for each of the clusters in Fig. 1 is an average spectrum of particles that possess similar fluorescence spectral features. On the other hand, the fluorescence spectra of aerosol collections are average spectra for a large number of particles of differing composition. These average spectra might be dominated by particles containing strong fluorophores. Further, aerosol particles in the collection will likely not have similar individual fluorescence spectra, and features of the spectra of single particles that make up the collection are likely smeared and maybe even lost due to averaging. The loss of fluorescence spectral information is particularly acute for particle clusters that have relatively small mass concentrations relative to the total concentration of fluorescent particles.

Keeping in mind this fundamental difficulty, we describe below our fluorescence spectral clusters and attempt to compare them to previous measurements of aerosol collections. We also compare to previous laboratory measurements of various organic carbon preparations that are relevant to atmospheric organic carbon aerosol; these comparisons we expect are more meaningful. However, we caution that the emission spectra of fluorophores can change depending on their local environment, complicating any clear interpretation of what organic compounds might be in particles populating the clusters. In a subsequent section we integrate the single-particle SPFS spectral data over a large number of particles (thereby smearing the spectra of single particles) in an attempt to provide a more meaningful comparison to measurements of atmospheric collections.

All our cluster spectral templates have a single peak, with the exception of cluster 11 . To be consistent with our earlier taxonomy (Pinnick et al., 2004), we number the clusters in order of increasing wavelength of the peak of the spectra, with the exception of clusters 9 and 11, which did not appear in the dominant clusters found previously at other sites.
Cluster 1's spectrum rises sharply toward shorter wavelengths but is cut off by the dimethylformamide liquid filter used to block the $263 \mathrm{~nm}$ probe laser. Previous measurements, from which this cluster was first identified (Pinnick et al., 2004), were obtained with an Intensified Charge Coupled Device (ICCD) camera. The ICCD has a better spectral resolution than the 32-anode PMT used here and revealed this peak to be around $300 \mathrm{~nm}$. Compounds having a single aromatic ring or an aromatic ring with a small degree of additional conjugation could fall into this cluster. Hill et al. (1999) found that tyrosine has a similar spectrum. Compounds found in organic carbon aerosol that may contribute include benzoic acids and phenols. Only a small fraction of fluorescent particles (on average $0.38 \%$ ) have spectra that fall in this cluster (Table 1 ). Because of the relatively small fraction of particles in this cluster, and since the fluorescence of particles in this cluster is not particularly intense, it is unlikely that features in this spectrum would be detectable in fluorescence measurements of aerosol, cloud, or fog water collections. There is considerable variability of the fraction of fluorescent particles populating this cluster at different sites and for different seasons: Pinnick et al. (2004) reported on average 3.4\% of fluorescent particles in this cluster in Maryland (MD) during spring 2003; Pan et al. (2007) reported 0.5\% in Connecticut during fall, and $1.2 \%$ in New Mexico during winter.

Cluster 2's spectrum peaks around $325 \mathrm{~nm}$ with a long tail extending to around $500 \mathrm{~nm}$. Compounds contributing to this cluster may include single-ring aromatics having additional conjugated bonds. Phenol and eugenol have a similar spectrum when excited at $280 \mathrm{~nm}$ (Chang and Thompson, 2010). Double-ring aromatics may contribute. A significant fraction of fluorescent particles (on average 6.0\%) populate this cluster, but less than found previously (23.7\% in MD in spring, $28.2 \%$ in CT in fall, and $13.8 \%$ in NM in winter).

Cluster 11's spectrum is bimodal with peaks around $315 \mathrm{~nm}$ and $575 \mathrm{~nm}$. Only $0.03 \%$ of fluorescent particles populate this cluster. One might wonder if these particles could possibly be mixtures of single-ring aromatics and flavins (including riboflavin). Flavins are essential cofactors in all living cells, and as such must be in a large fraction of PBAP. However, the $570 \mathrm{~nm}$ peak appears to be too narrow to be pure riboflavin (Hill et al., 1999). Because of the very low SPFS count rate for particles in this cluster it will not be considered further in this report.

Cluster 4's spectrum is similar to that of pure tryptophan (Pinnick et al., 2004) and is characteristic of bacteria and tryptophan-containing proteins. Other double ring aromatic compounds may have similar spectra. On average only $1.6 \%$ of

Table 1

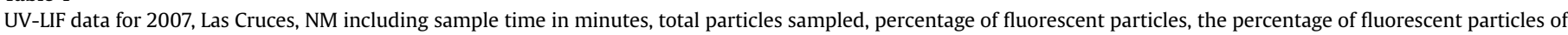
each spectral cluster, the sum thereof, and the percentage of particles not falling in any cluster.

\begin{tabular}{|c|c|c|c|c|c|c|c|c|c|c|c|c|c|c|c|}
\hline \multirow[t]{2}{*}{ Date } & \multirow[t]{2}{*}{ Time $^{\mathrm{a}}$} & \multirow{2}{*}{$\begin{array}{l}\text { Total } \\
\text { particles }^{\mathrm{b}}\end{array}$} & \multirow[t]{2}{*}{$\% \mathrm{Flu}^{\mathrm{c}}$} & \multicolumn{10}{|c|}{ Percentage of particles in each cluster ${ }^{\mathrm{d}}$} & \multirow[t]{2}{*}{ Sum } & \multirow{2}{*}{$\begin{array}{l}\% \text { No } \\
\text { fit }\end{array}$} \\
\hline & & & & $\begin{array}{l}\text { Cluster } \\
8\end{array}$ & $\begin{array}{l}\text { Cluster } \\
5\end{array}$ & $\begin{array}{l}\text { Cluster } \\
9\end{array}$ & $\begin{array}{l}\text { Cluster } \\
2\end{array}$ & $\begin{array}{l}\text { Cluster } \\
4\end{array}$ & $\begin{array}{l}\text { Cluster } \\
7\end{array}$ & $\begin{array}{l}\text { Cluster } \\
10\end{array}$ & $\begin{array}{l}\text { Cluster } \\
6\end{array}$ & $\begin{array}{l}\text { Cluster } \\
1\end{array}$ & $\begin{array}{l}\text { Cluster } \\
11\end{array}$ & & \\
\hline May 3-4 & 1344 & $3,774,474$ & 6.7 & 60.8 & 10.9 & 6.5 & 3.7 & 3.2 & 2.5 & 0.4 & 0.5 & 0.3 & $<0.1$ & 88.6 & 11.4 \\
\hline May $10-11$ & 1176 & $1,958,641$ & 26.1 & 64.3 & 11.7 & 6.8 & 5.0 & 1.1 & 0.2 & 0.4 & 0.7 & 0.3 & $<0.1$ & 90.4 & 9.6 \\
\hline May $17-18$ & 1128 & 983,946 & 31.0 & 60.6 & 8.5 & 10.1 & 5.7 & 1.1 & 0.2 & 1.3 & 0.2 & 0.6 & 0.1 & 88.2 & 11.8 \\
\hline May $22-23$ & 984 & $2,622,732$ & 27.3 & 61.5 & 9.5 & 10.1 & 9.5 & 1.0 & 0.1 & 0.2 & $<0.1$ & 0.4 & $<0.1$ & 92.3 & 7.7 \\
\hline Average & & & 22.8 & 61.8 & 10.1 & 8.4 & 6.0 & 1.6 & 0.8 & 0.6 & 0.4 & 0.4 & $<0.1$ & 89.9 & 10.1 \\
\hline $\operatorname{Jan} 22-24^{\mathrm{e}}$ & 2880 & 58,260 & 17.4 & 39.4 & 10.7 & 17.4 & 13.8 & 1.5 & 1.3 & 4.3 & 0.5 & 1.2 & 0.9 & 91.0 & 9.0 \\
\hline
\end{tabular}

\footnotetext{
a Approximate sample time in minutes; starting sample times are 10:57, 09:42, 13:17, and 9:27 for the four data ensembles.

b Total particles sampled by the PFS with size greater than about 1 micron.

c Percentage of total particles sampled with fluorescence above the noise floor.

d Note that this is the percentage of fluorescent particles, not the percentage of total particles.

e Total particles sampled with size greater than about 3 micron (from Pan et al., 2007).
} 
fluorescent particles populate this cluster. This cluster was populated more in MD-spring ( $8.3 \%$ of fluorescent particles), but about the same in CT-fall (1.3\%) and NM-winter (1.5\%).

Cluster 5's spectrum exhibits a peak at $370 \mathrm{~nm}$, with a fairly broad tail extending to about $600 \mathrm{~nm}$. Photolyzed pyruvic acid solutions, designed to mimic optical properties of HULIS substances, have spectra similar to this cluster, but with less of a tail (Rincon et al., 2009). The Rincon data reveals a broad fluorescence emission peak varying from about $390 \mathrm{~nm}$ (290 nm excitation) to about $430 \mathrm{~nm}$ (350 nm excitation). Thus, judging from this trend in the Rincon data, a shorter $263 \mathrm{~nm}$ excitation (used in the SPFS) could result in peak emission close to the observed $370 \mathrm{~nm}$ peak in cluster 5. Synchronous fluorescence scan spectra (having a constant difference of $20 \mathrm{~nm}$ between excitation and emission wavelengths) of collections of marine aerosol (Oppo et al., 1999) strongly resemble cluster 5, but we suspect spectra for their marine aerosol collection for a single excitation wavelength at $263 \mathrm{~nm}$ may be somewhat different. On average $10.1 \%$ of fluorescent particles populate this cluster. Curiously, this cluster is populated more uniformly for fluorescent organic carbon aerosol data collected at different geographic sites and seasons than any other clusters (Pan et al., 2007 report 10.8\% in MD-spring, $14.0 \%$ in CT-fall, and 10.7\% in NM-winter).

Cluster 6's spectrum has a rather sharp peak near $380 \mathrm{~nm}$. This spectrum occurs on average in only $0.38 \%$ of fluorescent particles, but is quite distinct and not believed to be noise. This cluster was previously found to have small concentrations of particles during spring in $\mathrm{MD}$ ( $0.5 \%$ of particles), during fall in $\mathrm{CT}(0.05 \%$ of particles $)$, and during winter in $\mathrm{NM}(0.5 \%$ of particles). The possible composition of particles populating this cluster remains a mystery. Because of the small fraction of particles in this cluster, the sharp peak characteristic of this spectrum would likely not be detectable in aerosol collections.

Cluster 7, a relatively sharp spectrum peaking near $440 \mathrm{~nm}$ with a short tail extending to about $600 \mathrm{~nm}$, is quite similar to spectra reported for cellulose (Olmstead and Gray, 1997). The occurrence of atmospheric cellulose has been suggested as a proxy for plant debris (Sanchez-Ochoa et al., 2007). Some pollens have similar spectra (Pan et al., 2011). This feature is also rare, occurring on average in only $0.77 \%$ of fluorescent particles. Previous measurements had a larger fraction in this cluster (3.2\% for spring in MD and fall in CT; $1.3 \%$ for winter in NM). These numbers are close to those found for the fraction of plant debris compared to total organic carbon in Europe (Sanchez-Ochoa et al., 2007).

Cluster 8's spectrum displays a broad peak centered at about $450-550 \mathrm{~nm}$ and is similar to spectra of an aerosolized sample of humic acid (reference sample $1 \mathrm{~S} 103 \mathrm{H}$ obtained from the International Humic Substances Society, St. Paul, MN, USA) measured with the SPFS (Fig. 2). Laboratory measurements of secondary organic aerosol formed by chemically-aged terpenes, also shown in Fig. 2, have slightly sharper spectra peaking around $420 \mathrm{~nm}$ (Bones et al., 2010). There are a number of measurements of fluorescent spectra of atmospheric collections and preparations of various organic compounds that are somewhat similar to cluster 8 . These are reviewed briefly in the supplement to this report and include: a) aqueous extracts of organic aerosol collections made in the Swiss Alps, at a rural site in Hungary, at several urban sites (Budapest, Auckland, and Christchurch), and at a maritime site in Mace Head, Ireland; b) fog water samples collected in the Po Valley, Italy; c) precipitation samples taken in Birmingham, UK; d) products of the spray combustion of diesel fuel; e) residue of a corn crop 8 months after harvest; f) certain distributions of PAHs; g) fulvic and humic acids derived from marine sediment samples; and $\mathrm{h}$ ) water-soluble dissolved organic matter in forest soil. The finding that LIF spectra of atmospheric collections generally have similarities to this cluster is consistent with the fact that this cluster has by far the largest

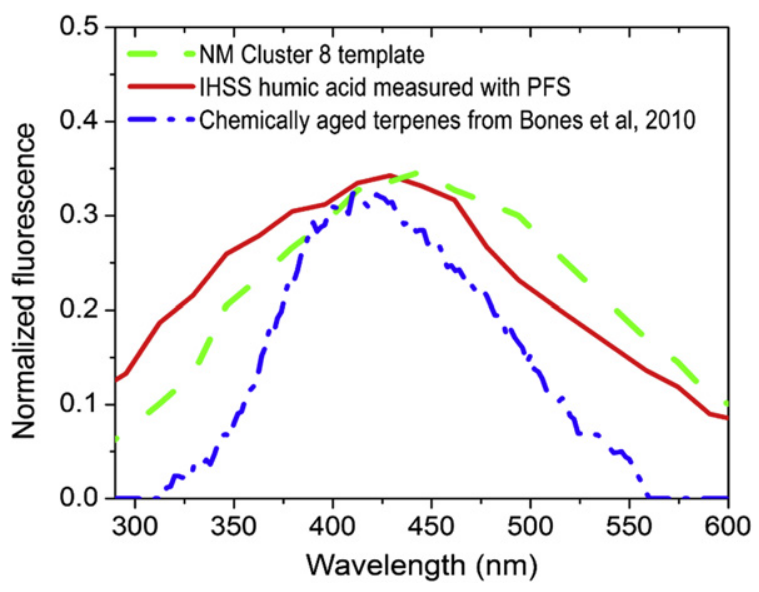

Fig. 2. A comparison of the NM cluster 8 template spectrum with UV-LIF spectra of aerosolized humic acid and with spectra of chemically-aged terpenes.

population of fluorescent particles (average of 61.8\%). A smaller fraction of particles populated this cluster in previous measurements (28.2\% for spring in MD, 33.5\% for fall in CT, and $39.4 \%$ for winter in NM). It is noteworthy that the fraction of fluorescent particles falling in this cluster is nearly the same for all data ensembles considered here, regardless of air mass trajectory or atmospheric condition.

Cluster 9's spectrum peaks around $340 \mathrm{~nm}$, has a shoulder around $450 \mathrm{~nm}$, and a long tail extending to $600 \mathrm{~nm}$. Some fungal spores and dry-dispersed "peat soil 2BS103P" samples from the International Humic Substances Society have somewhat similar spectra (Fig. 3). The condensed samples of the exhaust products of internal combustion gasoline engines (Merola et al., 2001) also have a similar spectrum. Previous measurements (Winiwarter et al., 2009 and refs therein) reveal that fungal spores and other primary biological particles are a major source of atmospheric biological aerosol. The possible contribution of both fungal spores and exhaust particles to this cluster is consistent with it being highly populated. Percentages of fluorescent particles in this cluster average $8.4 \%$.

Cluster 10's spectrum is similar to that of cluster 8 but has a prominent $570 \mathrm{~nm}$ peak which could be due to riboflavin in PBAP.

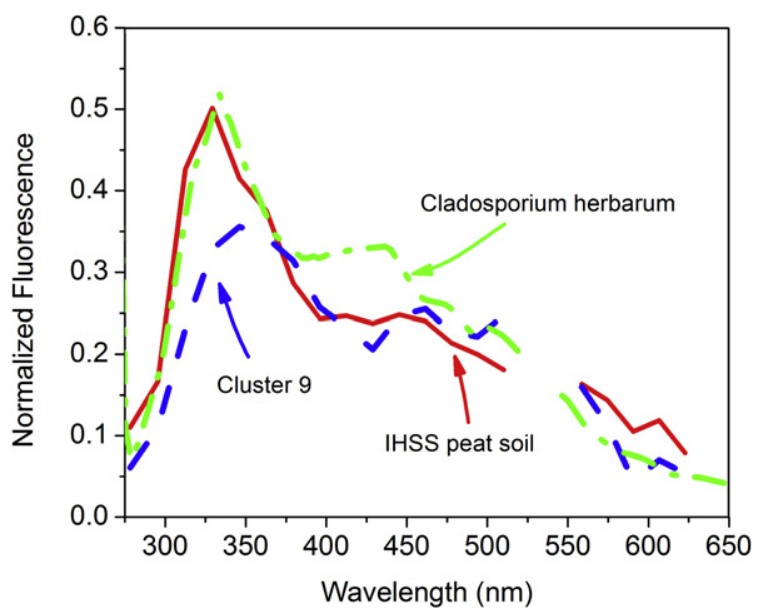

Fig. 3. A comparison of the NM cluster 9 template spectra with UV-LIF spectra of a sample of aerosolized Cladosporium fungal spores (Pan et al., 2011) and spectra of aerosolized peat soil (obtained from IHSS and measured by SPFS). 
It is possible, but unlikely, that the $570 \mathrm{~nm}$ peak is associated with the uranium mineral boltwoodite, (a minor component in soil in the vicinity of uranium mining activities) which has a minor fluorescence peak at $567 \mathrm{~nm}$ when excited at $266 \mathrm{~nm}$ (Arnold and Baumann, 2009). Particles in cluster 10 are rare (occurring on average in only $0.53 \%$ of fluorescent particles).

For the four days of May 2007 data examined here, on average $22.8 \%$ of particles have fluorescence above noise (Table 1 ) with considerable variability. By far the most populated cluster of fluorescent particles is cluster 8 , with an average of $61.8 \%$ of fluorescent particles, followed by cluster 5 with $10.0 \%$ of particles; cluster 9 with $8.4 \%$; cluster 2 with $6.0 \%$; cluster 4 with $1.6 \%$; cluster 7 with $0.8 \%$, cluster 10 with $0.6 \%$, and clusters 6 and 1 with $0.4 \%$ of fluorescent particles. The fraction of fluorescent particles populating the various clusters is in general remarkably similar for the different data sets. An exception is for some clusters in the May 3-4 data set, where the percentage of particles falling in cluster 4 is three times that of other data sets, and those populating cluster 7 is 10-20 times that of other data sets.

As described above, even though the fluorescence spectra of organic carbon particles can only be used for rudimentary classification of particle composition, a significant advantage of our single-particle SPFS system is that it provides the capability to measure the concentration variability of fluorescent particles having different spectral features. This variability we investigate in the next section.

\section{Time series of aerosol measurements}

The time series of aerosol measurements for May 3-4 and May 22-23, 2007 are presented in Fig. 4; similar data exists for May 1011 and May 17-18. The nephelometer red channel data are averaged over $4 \mathrm{~min}$ periods. A summary of the nephelometer red, green, and blue channel data for all four May 2007 data sets, together with temperature and relatively humidity data, appear in Table 2.

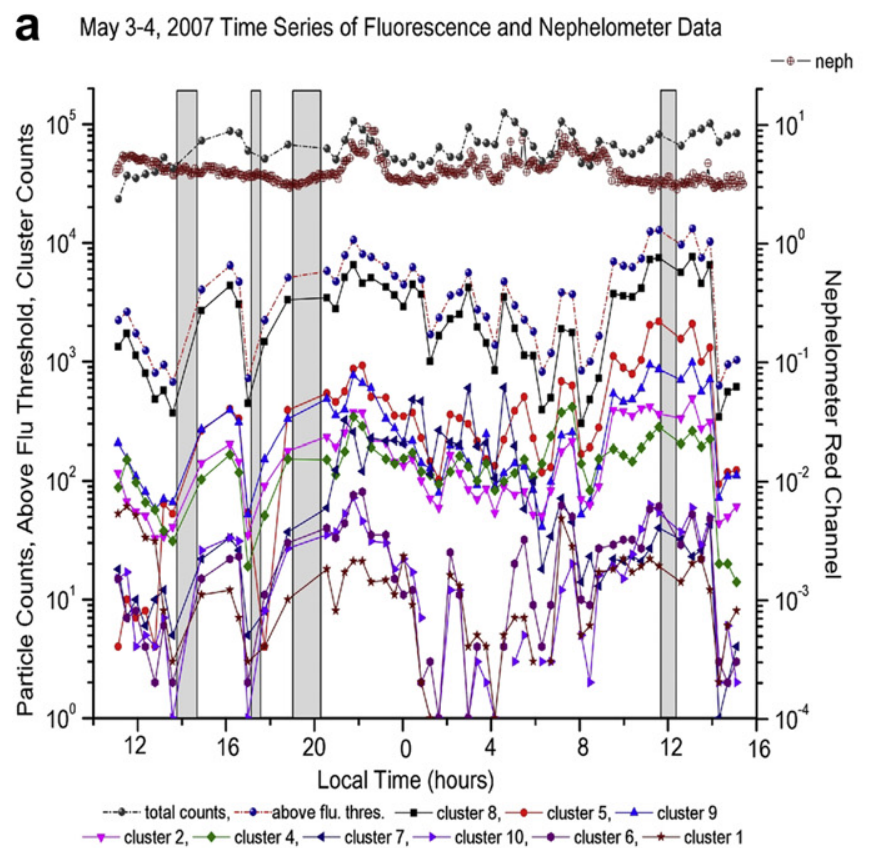

The SPFS data is presented in terms of total counts accumulated over 24 min periods; absolute particle concentrations and size distributions would be difficult to precisely determine because of the size-dependent sample rate of the aerosol virtual-impactor concentrator/SPFS system. The SPFS data includes: the total aerosol particle count (for sizes greater than about $1 \mu \mathrm{m}$ ), the counts for particles having fluorescence above threshold, and the counts for particles having spectra falling in various spectral clusters (all accumulated over 24 min intervals). The population of particles in various clusters varies from more than $10^{4}$ counts (for cluster 8 ) to only a few counts (for clusters 6, 7,10 and 1). Cluster 11 data is not shown because it is not statistically credible. The shaded areas in the figures indicate time intervals when the SPFS nozzle was plugged, or when the system was cleaned and calibrated. Data points sometimes appear within the shaded areas because of our averaging scheme. Some general findings for the time series of aerosol data are as follows:

a. Averages of the nephelometer red channel scattering ratios (Table 2 ) suggest the heaviest overall aerosol loading for May 22-23; moderate aerosol loading for May 3-4 and May 17-18; and relatively low aerosol loading for May 10-11 (a red channel scattering ratio of 5 or more indicates a relatively high aerosol loading).

b. Although no precise particle size measurements were made, nephelometer scattering ratios (red-to-blue; green-to-blue; red-to-green) indicate the largest particles for May 3-4 and May 22-23; the smallest for May 10-11 and May 17-18.

c. Differences in atmospheric temperatures for the data sets are small; but significantly higher relative humidities exist for the May 17-18 data.

d. The concentrations of particles in the most populated clusters $(8,5,9,2)$ appear highly correlated for all time-series of data.

One striking feature of the SPFS data evident here, and found previously (Pinnick et al., 2004), is that the fraction of fluorescent

\section{b May 22-23, 2007 Time Series of Fluorescence and Nephelometer Data}

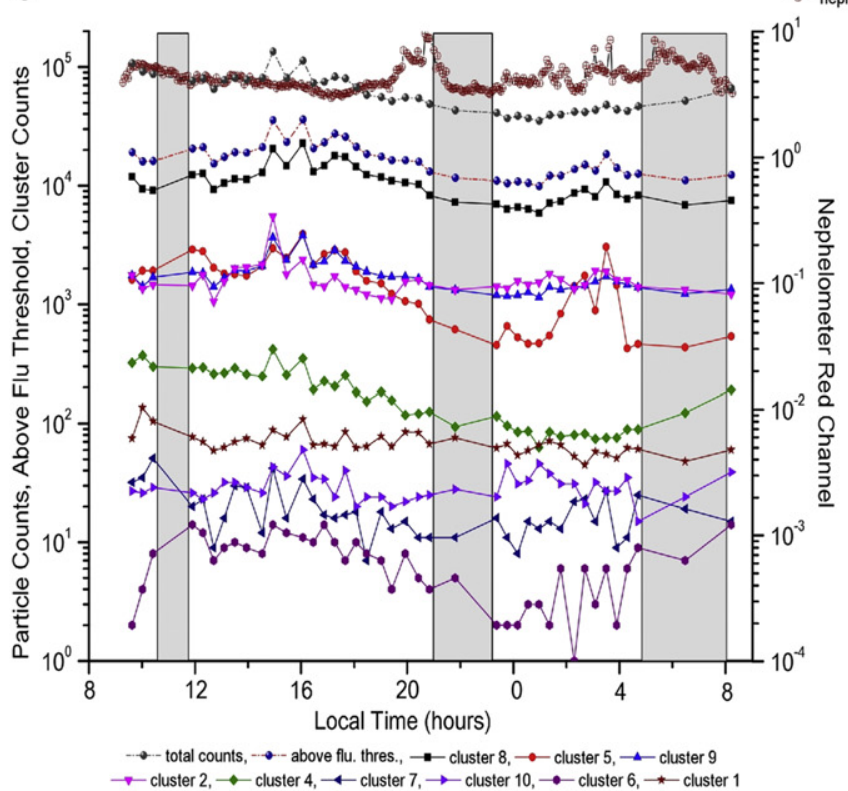

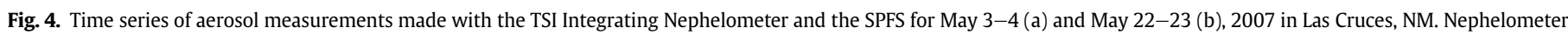

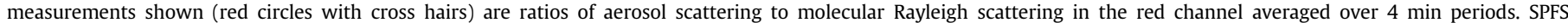

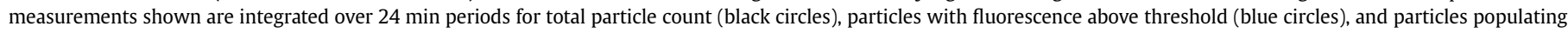
various clusters. 
Table 2

Summary of integrating nephelometer and meteorological data for May 2007, Las Cruces, NM, USA.

\begin{tabular}{|c|c|c|c|c|c|c|c|c|}
\hline Date & $\begin{array}{l}\text { Temp range } \\
(\operatorname{deg} C)\end{array}$ & $\begin{array}{l}\text { Avg. temp } \\
(\operatorname{deg} C)\end{array}$ & $\begin{array}{l}\text { RH range } \\
\text { (percent) }\end{array}$ & $\begin{array}{l}\text { Avg. RH } \\
\text { (percent) }\end{array}$ & $\begin{array}{l}\text { Neph red } \mathrm{ch}^{\mathrm{c}} \\
\text { ratio to molec. }\end{array}$ & $\begin{array}{l}\text { Neph ratio } \\
\text { red to blue }\end{array}$ & $\begin{array}{l}\text { Reph ratio } \\
\text { green to blue }\end{array}$ & $\begin{array}{l}\text { Neph ratio } \\
\text { red to green }\end{array}$ \\
\hline May 34 & $20.2-28.3$ & 24.6 & $9.3-30.9$ & 18.6 & 4.34 & 4.51 & 2.32 & 1.95 \\
\hline May 10-11 & $21.6-29.6$ & 25.8 & $10.9-33.6$ & 21.8 & 2.65 & 3.27 & 1.93 & 1.69 \\
\hline May $17-18$ & $21.6-27.6$ & 24.7 & $25.1-46.6$ & 37.3 & 4.47 & 2.92 & 1.77 & 1.65 \\
\hline May $22-23$ & $22.6-28.5$ & 25.4 & $6.3-23.7$ & 13.7 & 5.59 & 4.47 & 2.28 & 1.96 \\
\hline
\end{tabular}

a Temperature range for the approximate $24 \mathrm{~h}$ data set.

b Relative humidity range for the approximate $24 \mathrm{~h}$ data set.

c Nephelometer red channel (average ratio to molecular scattering).

d Nephelometer scattering ratio (average red channel to blue channel).

e Nephelometer scattering ratio (average green channel to blue channel).

${ }^{f}$ Nephelometer scattering ratio (average red channel to green channel).

particles falling in the various spectral clusters appears to remain relatively constant for periods of several weeks at a particular site. So it may not be too surprising that at least some of the concentrations of particles in different clusters might be correlated over much shorter time scales, as is evident in Fig. 4. In the next section we pursue more quantitatively this time correlation.

\section{Time series correlations of concentrations of particles populating different spectral clusters}

To quantitatively examine this time correlation we calculated Pearson correlation coefficients for each (approximate $24 \mathrm{~h}$ ) time series of fluorescent aerosol data. The results are summarized in Table 3. A Pearson coefficient of 1 indicates perfect time-series correlation; a coefficient of 0 indicates no correlation; a coefficient of -1 perfect anti-correlation. The clusters are listed in order of the most populated cluster (on average) to the least populated cluster. A summary of the results follows: a. As noted above, the concentrations of particles in the most populated clusters $(8,5,9,2)$ are in general highly correlated (with correlation coefficients exceeding 0.6) for all May data sets, with few exceptions. On average, about $86 \%$ of all fluorescent particles fall in these four spectral clusters.

b. The most highly correlated concentrations are clusters 9 and 2, 9 and 5,8 and 9 , and 8 and 5 .

c. Overall least correlated concentrations are for spectral clusters having small percentages of fluorescent particles: 7 and 6, 7 and 10,1 and 10,1 and 6 .

d. The populations of particles in cluster 7 are generally uncorrelated with those in the other clusters.

e. For the May 3-4 data ensemble the concentration of particles in both highly populated clusters $(8,5,9$, and 2$)$ and some weakly populated clusters ( 10 and 6 ) are highly correlated. We have no good explanation for this distinct difference in the May 3-4 data ensemble, but note that the fraction of fluorescent particles in the data is only about $1 / 4$ th that of the other data

Table 3

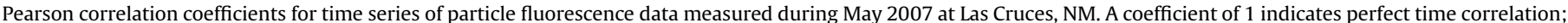

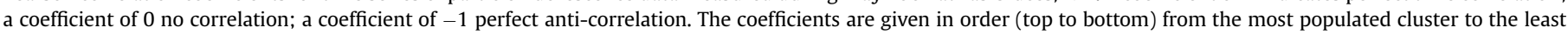
populated cluster.

\begin{tabular}{|c|c|c|c|c|c|c|c|c|c|}
\hline & & Cluster 5 & Cluster 9 & Cluster 2 & Cluster 4 & Cluster 7 & Cluster 10 & Cluster 6 & Cluster 1 \\
\hline May 3-4 & Cluster 8 & 0.84 & 0.91 & 0.85 & 0.59 & 0.27 & 0.86 & 0.69 & 0.12 \\
\hline May $10-11$ & Cluster 8 & 0.51 & 0.54 & 0.45 & 0.57 & 0.87 & -0.22 & 0.52 & 0.16 \\
\hline May $17-18$ & Cluster 8 & 0.87 & 0.71 & 0.63 & 0.67 & 0.51 & -0.06 & -0.16 & 0.58 \\
\hline May $22-23$ & Cluster 8 & 0.86 & 0.97 & 0.51 & 0.69 & 0.38 & 0.28 & 0.63 & 0.39 \\
\hline May 3-4 & Cluster 5 & & 0.92 & 0.89 & 0.64 & -0.11 & 0.78 & 0.74 & 0.14 \\
\hline May $10-11$ & Cluster 5 & & 0.65 & 0.66 & 0.76 & 0.31 & 0.25 & 0.91 & 0.31 \\
\hline May $17-18$ & Cluster 5 & & 0.69 & 0.66 & 0.82 & 0.48 & -0.10 & 0.09 & 0.45 \\
\hline May $22-23$ & Cluster 5 & & 0.80 & 0.37 & 0.70 & 0.47 & 0.20 & 0.60 & 0.37 \\
\hline May 3-4 & Cluster 9 & & & 0.94 & 0.63 & -0.10 & 0.91 & 0.80 & 0.21 \\
\hline May $10-11$ & Cluster 9 & & & 0.94 & 0.76 & 0.34 & -0.04 & 0.65 & 0.34 \\
\hline May $17-18$ & Cluster 9 & & & 0.68 & 0.72 & 0.56 & -0.39 & -0.17 & 0.79 \\
\hline May $22-23$ & Cluster 9 & & & 0.65 & 0.65 & 0.43 & 0.39 & 0.61 & 0.39 \\
\hline May 3-4 & Cluster 2 & & & & 0.66 & -0.09 & 0.85 & 0.80 & 0.23 \\
\hline May $10-11$ & Cluster 2 & & & & 0.75 & 0.20 & 0.05 & 0.68 & 0.36 \\
\hline May $17-18$ & Cluster 2 & & & & 0.73 & 0.33 & -0.03 & 0.17 & 0.44 \\
\hline May $22-23$ & Cluster 2 & & & & 0.44 & 0.46 & 0.37 & 0.31 & 0.22 \\
\hline May 3-4 & Cluster 4 & & & & & 0.05 & 0.62 & 0.81 & 0.34 \\
\hline May $10-11$ & Cluster 4 & & & & & 0.32 & 0.20 & 0.80 & 0.52 \\
\hline May $17-18$ & Cluster 4 & & & & & 0.45 & -0.29 & 0.18 & 0.46 \\
\hline May $22-23$ & Cluster 4 & & & & & 0.63 & 0.20 & 0.59 & 0.65 \\
\hline May 3-4 & Cluster 7 & & & & & & -0.07 & -0.10 & -0.25 \\
\hline May $10-11$ & Cluster 7 & & & & & & -0.15 & 0.31 & 0.06 \\
\hline May $17-18$ & Cluster 7 & & & & & & -0.21 & -0.06 & 0.45 \\
\hline May $22-23$ & Cluster 7 & & & & & & 0.14 & 0.30 & 0.56 \\
\hline May 3-4 & Cluster 10 & & & & & & & 0.83 & 0.25 \\
\hline May $10-11$ & Cluster 10 & & & & & & & 0.32 & 0.19 \\
\hline May $17-18$ & Cluster 10 & & & & & & & 0.38 & -0.37 \\
\hline May $22-23$ & Cluster 10 & & & & & & & 0.09 & 0.26 \\
\hline May 3-4 & Cluster 6 & & & & & & & & 0.32 \\
\hline May $10-11$ & Cluster 6 & & & & & & & & 0.44 \\
\hline May $17-18$ & Cluster 6 & & & & & & & & -0.41 \\
\hline May $22-23$ & Cluster 6 & & & & & & & & 0.19 \\
\hline
\end{tabular}


ensembles (see Table 1), and that the wind trajectories and aerosol concentrations are highly variable compared to other time series of data.

The observed strong correlation of concentrations of particles in highly populated clusters is striking; also noteworthy is the weak correlation of cluster 7 with all other clusters. We hypothesize that particles in highly correlated clusters have the same source regions. To investigate this hypothesis, we performed an air mass trajectory analysis for this site and present the results in the following section.

\section{Air mass trajectory analysis}

We give the details of a $48 \mathrm{~h}$ air mass trajectory analysis in the supplement to this report. A summary of the analysis follows:

The May 3-4 backward trajectories initially (for the first $18 \mathrm{~h}$ ) arrive from the southwest originating from the Baha Peninsula and the Gulf of California. Then, over the next $6 \mathrm{~h}$ the trajectories rapidly move clockwise to the west, coming from Arizona and western NM. During the final $6 \mathrm{~h}$ of the approximate $24 \mathrm{~h}$ sampling period the trajectories continue to move clockwise, with decreasing winds, and eventually come from the east-northeast by the end of the sampling period.

The May 10-11 trajectories are generally associated with period of low surface winds. During the first 6 h they arrive from the eastnortheast (from eastern NM). Over the next $18 \mathrm{~h}$ they migrate to the west coming north-northwest of the sampling site, and then (over the final $6 \mathrm{~h}$ ) migrate to the northeast (coming from eastern NM) at the end of the sampling period.

The May 17-18 trajectories are nearly constant over the sampling period, coming from the east-northeast through west and north Texas, Oklahoma, Kansas, and Nebraska.

The May 22-23 trajectories are again nearly constant over the sampling period, coming from the southwest through Mexico from the Baha Peninsula and the Gulf of California.

\section{Possible sources of fluorescent aerosol particles}

The above sections reveal a myriad of results for the four May 2007 New Mexico data regarding the scattering characteristics of total aerosol, relative concentrations of the fluorescent aerosol fraction, the concentrations of fluorescent particles falling in various fluorescence spectral clusters, the time dependence of these concentrations, the temporal correlation of particle concentrations populating various clusters, and the wind trajectories that reveal possible regional sources of aerosol particles. Based on these results we suggest possible sources and compositions of fluorescent particles measured at the sampling site.

The concentrations of particles in clusters 8, 5, 9 and 2, which comprise on average between 81.8 and $90.5 \%$ of fluorescent particles, are highly correlated in each (approximate $24 \mathrm{~h}$ ) time series, regardless of air mass trajectory. The $(48 \mathrm{~h}$ ) back-trajectories for the different data ensembles are distinctly different, particularly the trajectories (for May 22-23) that come from the Gulf of California (which should have maritime influence), and the trajectories (for May 17-18) that come from west Texas, Oklahoma, Kansas, and Nebraska (which should have little maritime influence). This suggests that the dominant populations of fluorescent particles in these clusters $(8,9,5,2)$ are either: a) formed perhaps within several hundreds of kilometers of the measurement site and have the same local regional source, or b) formed and/or aerosolized at similar relative concentrations whether generated locally or far away.
We note that there is little evidence for a rise in the concentration of aerosols during the rush hour traffic periods occurring around $0730-0830$ and $1630-1730$ local time as seen for example in Fig. 4. The traffic during other periods is relatively light. This suggests that the contribution of aerosol from local vehicular traffic to the overall aerosol burden is small.

We may conjecture, on the basis of the descriptions of the possible compositions of particles populating the clusters in section 6 , that clusters 8,5 , and 2 might be populated mostly by particles containing secondary organic aerosol (SOA) formed by gas-to-particle reactions. The SOA material may have condensed on weakly fluorescent particles such as soil dust, forming fluorescent super-micron particles as observed here. Cluster 9 might be populated at least partially by PBAP such as fungal spores, which would be directly injected into the atmosphere. Since dust particles of soil origin are also directly injected into the atmosphere, the possible coating of SOA on soil dust might explain why the populations of particles in cluster $8,5,9$ and 2 are so well correlated. Note that this attribution of a high percentage of the total fluorescent particles to a combination of fluorescent SOA and SOA mixed with soil dust: i) is a deviation from the more common view that most of the fluorescent particles in the atmosphere are attributable to PBAP; and ii) may be difficult to reconcile with our finding that the correlated clusters have such different spectral shapes. Further measurements are needed to investigate the generality of the high correlation of the most populated clusters.

The population of particles in cluster 7 is in general uncorrelated with other clusters (Table 3). Cellulose would be contained in plant debris and fractionated pollen, but not a part of fungal material or debris from animals (Winiwarter et al., 2009). Interestingly, the fraction of fluorescent particles falling in this cluster is small (average $0.77 \%$ ), suggesting less of a contribution of plant debris to organic carbon aerosol at this desert site than in Maryland and Connecticut (Pan et al., 2007), and in Europe (Sanchez-Ochoa et al., 2007).

\section{Integrated SPFS LIF spectra compared to fluorescence spectra of filter collections}

The time series of LIF cluster data presented in section 7 reveal the concentration variability for particles having different fluorescence spectra. But these results do not specifically reveal what LIF spectra would be expected for a collection of aerosol particles as reported in the literature. In an attempt to mimic the LIF spectra of aerosol collections we integrated the SPFS LIF spectral measurements for single particles over relatively long (approximately $24 \mathrm{~h}$ ) time intervals for the May 2007 data ensembles. In these integrations the fluorescence spectra are not normalized, and so particles having strong fluorescence are appropriately weighted more than particles having weak fluorescence. A noteworthy caveat regarding comparison of fluorescence spectra from the SPFS with filter collections is that the SPFS measures aerosol particles in situ; volatile particles that might evaporate from the filter medium in a collection are not missed by the SPFS system.

Another important caveat in our attempt to mimic the LIF spectra of an aerosol collection has to do with employment of the virtual impactor concentrator upstream from the inlet of the SPFS, and the resulting size-dependent sample rate of the concentrator/ SPFS system. As noted previously, the purpose of the concentrator is to enhance the concentration of super-micron-sized particles over those of micron-sized particles in an attempt to partially compensate for their much smaller concentration in the atmosphere, so that significant numbers of super-micron particles can be sampled at rates comparable to that for micron-sized particles. 
Thus the aerosol concentrator increases the effective sample rate of the SPFS by a factor of about one hundred for nominal $5-\mu \mathrm{m}$ particles (where the concentrator works most efficiently) compared to aerodynamically small (nominal $1-\mu \mathrm{m}$ ) and large (nominal $10-\mu \mathrm{m}$ ) particles. As a result, the integrated LIF spectra skewed preferentially toward weighting more heavily the spectra of particles having aerodynamic diameter around 3-7 $\mu \mathrm{m}$.

Keeping in mind this caveat, the integrated LIF spectra for the May 2007 data appear in Fig. 5; each are broad over the entire 280$600 \mathrm{~nm}$ wavelength range, but reveal small peaks around $350 \mathrm{~nm}$ and $450 \mathrm{~nm}$.

These integrated spectra can be compared to previous measurements made on aerosol collections. As mentioned above, previous measurements are only for the water soluble fraction of aerosol collections and not for the entire aerosol filter sample. The fluorescence measurements made on the WSOC fraction of aerosol collected at a mountain site in Switzerland, at a rural site in Hungary, and at sites in Auckland and Christchurch, New Zealand; Budapest, Hungary; and Mace Head, Ireland (Krivacsy et al., 2008 and refs therein) all reveal a broad single fluorescence peak emission around $400 \mathrm{~nm}$ when excited at $235 \mathrm{~nm}$, which the authors attribute to HULIS. For $263 \mathrm{~nm}$ excitation (as in the SPFS system) these peaks might be red-shift close the observed $450 \mathrm{~nm}$ peak in Fig. 5. The second peak at $350 \mathrm{~nm}$ measured by our SPFS could possibly be from non-soluble PBAP particles such as fungal spores, pollens, and bacteria, or possibly from chemical aging of biogenic terpenes (Bones et al., 2010). The results suggest previous fluorescence measurements of the WSOC fraction of aerosol collections may be missing an important fraction of fluorescent particles that are not water-soluble.

\section{Time series of integrated LIF spectra}

Having shown that there is some variability in integrated LIF spectra for measurements made over a month at a single site we pose the question: is there variability in integrated LIF spectra over even shorter time scales? To at least partially answer this question we preformed integrations over relatively short $(24 \mathrm{~min})$ time intervals for each of the May 2007 data ensembles. This time interval is sufficiently short that a meaningful time-series of LIF spectra can be obtained, but yet sufficiently long that the fluorescence signals from a large number of particles are integrated to alleviate signal-to-noise and other statistical issues.

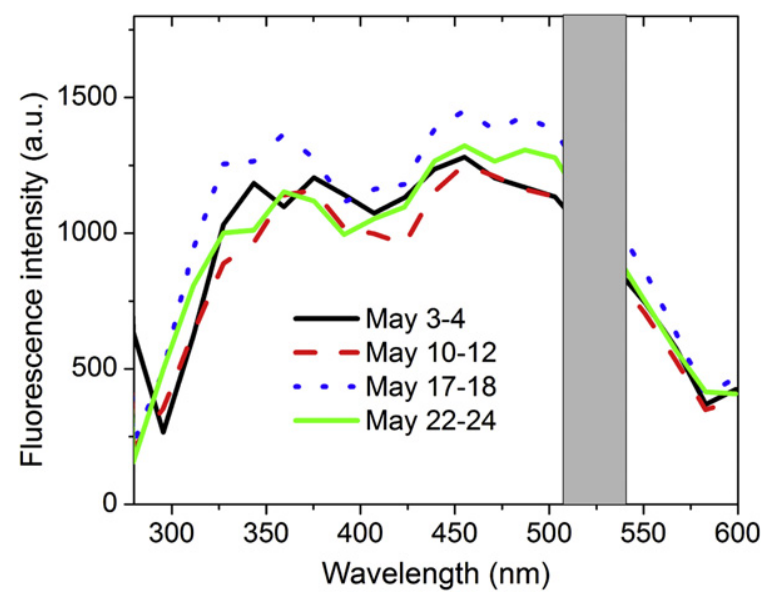

Fig. 5. Integrated UV-LIF spectra of atmospheric aerosol measured with the SPFS for May 2007 in Las Cruces, NM. Each spectrum represents an approximate 24 h integration of between about 1 and 4 million un-normalized single particle spectra.

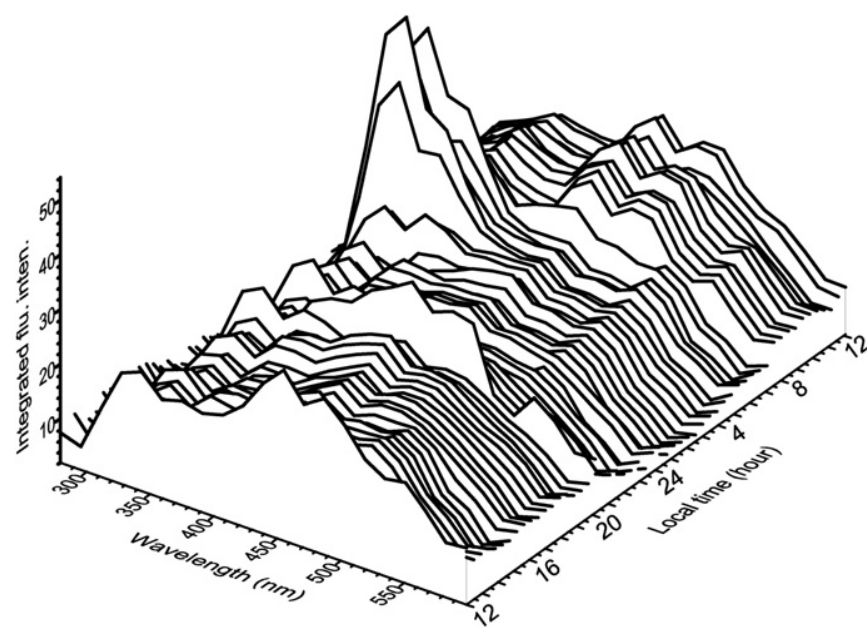

Fig. 6. Integrated UV-LIF spectra of atmospheric aerosol particles obtained with the SPFS during May 3-4, 2007 in Las Cruces, NM. Each spectrum represents a 24 min integration of un-normalized single particle spectra. Variability in spectra with the prominent $350 \mathrm{~nm}$ peak is clearly evident.

A sample of the (24-min integrated) LIF spectra obtained from SPFS measurements is shown in Fig. 6 for the May 3-4 2007 data. The LIF spectra appear as a time series with each spectrum representing a 24 min integration of the SPFS data. Most of the spectra are very broad and resemble those of cluster 8 (characteristic of chemically aged terpenes/humic substances), consistent with the fact that this cluster's spectral features occur in about $61 \%$ of fluorescent particles. However, some of the spectra have a distinctive second fluorescence peak around $350 \mathrm{~nm}$. It is clear from the time series that for most measurement periods the integrated spectra show only small variability; however, the prominent peak centered around $350 \mathrm{~nm}$ (with a slight tail) reveals transients that last for less than 1-2 h. This transient fluorescence feature could derive from PBAP such as fungal spores (spectra that might populate cluster 9) and bacteria (spectra that might populate cluster 4). We note that on average clusters 9 and 4 together are populated by $9.7 \%$ of fluorescent particles for the May 3-4 data ensemble.

\section{Concluding remarks}

a. A rather compelling finding of this study is that the concentrations of particles in the most populated fluorescence spectral clusters $(8,5,9$, and 2$)$ are in general highly correlated for each time series of data, regardless of air mass trajectory or atmospheric condition. The preferential sampling of supermicron particles by the virtual impactor concentrator could contribute to this high correlation. It might be possible that the majority of the particles in most of these clusters could derive from fluorescent SOA compounds condensing onto particles directly injected into the atmosphere (presumably by wind action on soil and plants, etc); however, it is not clear under this scenario how such different spectral shapes of fluorescent particles could be produced.

b. The finding that the populations of particles in the celluloselike cluster 7 are generally uncorrelated with concentrations of particles in any other cluster is also striking.

c. The integrated fluorescence spectral data intended to mimic that of an approximate $24 \mathrm{~h}$ aerosol collection reveal bimodal spectral profiles for all data sets with peaks around $350 \mathrm{~nm}$ and $450 \mathrm{~nm}$. So far as we know the $350 \mathrm{~nm}$ peak has not been found heretofore in aerosol collections; but these collections have not included the non-water soluble aerosol fraction. This 
is consistent with the conjecture that the $350 \mathrm{~nm}$ peak derives from PBAP that are not water-soluble.

d. The fluorescence spectral data integrated over $24 \mathrm{~min}$ time periods reveal relatively uniform spectral profiles over periods of about $24 \mathrm{~h}$, except for occasional strong emission peaks around $350 \mathrm{~nm}$ wavelength that have significant variability over periods of $1-2 \mathrm{~h}$. Enhanced concentrations of PBAP such as fungal spores derived from gusty or variable local wind fields near the sampling site could account for this variability.

e. It is unclear at present how classification of organic aerosol particles using UV-LIF spectra can be compared to other methods; for example the use of saccharides as molecular markers in aerosol collections (Jia et al., 2010), or the use of single-particle mass spectrometry to identify molecular fragments (Murphy et al., 2006). Joint experiments where different classification techniques could be compared would be useful.

\section{Acknowledgments}

This research was supported by the Defense Threat Reduction Agency under the Physical Science and Technology Basic Research Program and by Army Research Laboratory mission funds. We thank David L. Bones and Professor Sergey Nizkorodov for supplying their fluorescence spectral data on chemically-aged terpenes.

\section{Appendix A. Supplementary material}

Supplementary material related to this article can be found at http://dx.doi.org/10.1016/j.atmosenv.2012.09.020.

\section{References}

Arnold, T., Baumann, N., 2009. Boltwoodite and compreignacite characterized by laser fluorescence spectroscopy. Spectrochimica Acta A 71, 1964-1968.

Bones, D.L., Henricksen, D.K., Mang, S.A., Gonsior, M., Bateman, A.P., Nguyen, T.B., Cooper, W.J., Nizkorodov, S.A., 2010. Appearance of strong absorbers and fluorophors in limonene- $\mathrm{O}_{3}$ secondary organic aerosol due to $\mathrm{NH}_{4}$-mediated chemical aging over long time scales. Journal of Geophysical Research 115, D05203.

Chang, J.L., Thompson, J.E., 2010. Characterization of colored products formed during irradiation of aqueous solutions containing $\mathrm{H} 2 \mathrm{O} 2$ and phenolic compounds. Atmospheric Environment 44, 541-551.

Hill, S.C., Pinnick, R.G., Pan, Y.L., Holler, S., Chang, R.K., Bottiger, J.R., Chen, B.T., Orr, C.-S., Feather, G., 1999. Real-time measurement of fluorescence spectra from single airborne biological particles. Field Analytical Chemistry \& Technology 3, 221-239.

Jia, Y., Bhat, S., Fraser, M.P., 2010. Characterization of saccharides and other organic compounds in fine particles and the use of saccharides to track primary biologically derived carbon sources. Atmospheric Environment 44, 724-732.

Junker, C., Sheahan, J., Jennings, S.G., O'Brien, P., Hinds, B.D., Martinez-Twary, E. Hansen, A.D.A., White, C., Garvey, D.M., Pinnick, R.G., 2004. Measurement and analysis of aerosol and black carbon in the Southwestern United States and Panama and their dependence on air mass origin. Journal of Geophysical Research 109 (D13201), 1-23.

Krivacsy, Z., Kiss, G., Ceburnis, D., Jennings, G., Maenhaut, W., Salma, I., Shooter, D., 2008. Study of water-soluble atmospheric humic matter in urban and marine environments. Atmospheric Research 87, 1-12.

Merola, S.S., Gambi, G., Allouis, C., Beretta, F., Borghese, A., D’Alessio, A., 2001 Analysis of exhausts emitted by i. c. engines and stationary burners by means of extinction and fluorescence spectroscopy. Chemosphere 42, 827-834.

Murphy, D.M., Cziczo, D.J., Froyd, K.K., Judson, P.K., Matthew, B.M., Middlebrook, A.M., Peltier, R.E., Sullivan, A., Thomson, D.S., Weber, R.J., 2006 Single-particle mass spectrometry of tropospheric aerosol particles. Journal of Geophysical Research 111, D23S32.

Olmstead, J.A., Gray, D.G., 1997. Fluorescence spectroscopy of cellulose, lignin and mechanical pulps: a review. Journal of Pulp and Paper Science 23, J571-J581.

Oppo, C., Bellandi, S., Degli Innocenti, N., Stortini, A.M., Loglio, G., Schiavuta, E., Cini, R., 1999. Surfactant components of marine organic matter as agents for biogeochemical fractionation and pollutant transport via marine aerosols. Marine Chemistry 63, 235-253.

Pan, Y., Hill, S.C., Pinnick, R.G., House, J.M., Flagan, R.C., Chang, R.K., 2011. Dualexcitation-wavelength fluorescence spectra and elastic scattering for differentiation of single airborne pollen and fungal particles. Atmospheric Environment 45, 1555-1563.

Pan, Y.L., Pinnick, R.G., Hill, S.C., Rosen, J.M., Chang, R.K., 2007. Single-particle laserinduced-fluorescence spectra of biological and other organic-carbon aerosols in the atmosphere: measurements at New Haven, CT and Las Cruces, NM, USA. Journal of Geophysical Research 112, D24S19.

Pinnick, R.G., Fernandez, G., Martinez, E., Hansen, A.D.A., Fuller, K., 1993. Aerosol in the southwestern US: measurements of mass concentration, volatility, size distribution, absorption characteristics, carbon content, and vertical structure to $7 \mathrm{~km}$ above sea level. Journal of Geophysical Research 98, 2651-2666.

Pinnick, R.G., Hill, S.C., Pan, Y.-L., Chang, R.K., 2004. Fluorescence spectra of atmospheric aerosol at Adelphi, Maryland, USA; measurement and classification of single particles containing organic carbon. Atmospheric Environment 38, $1657-$ 1672

Rincon, A.G., Guzman, M.I., Hoffmann, M.R., Colussi, A.J., 2009. Optical absorptivity versus molecular composition of model organic aerosol matter. Journal Physical Chemistry A 113, 10512-10520.

Rosen, J.M., Pinnick, R.G., Garvey, D.M., 1997. Nephelometer optical response mode for the interpretation of atmospheric aerosol measurements. Applied Optics 36, 2642-2649.

Sanchez-Ochoa, A., Kasper-Giebl, A., Puxbaum, H., Gelencser, A., Legrand, M., Pio, C., 2007. Concentration of atmospheric cellulose: a proxy for plant debris across a west-east transect over Europe. Journal of Geophysical Research 112, D008180.

Winiwarter, W., Bauer, H., Caseiro, A., Puxbaum, H., 2009. Quantifying emissions of primary biological aerosol particle mass in Europe. Atmospheric Environment 43, 1403-1409. 